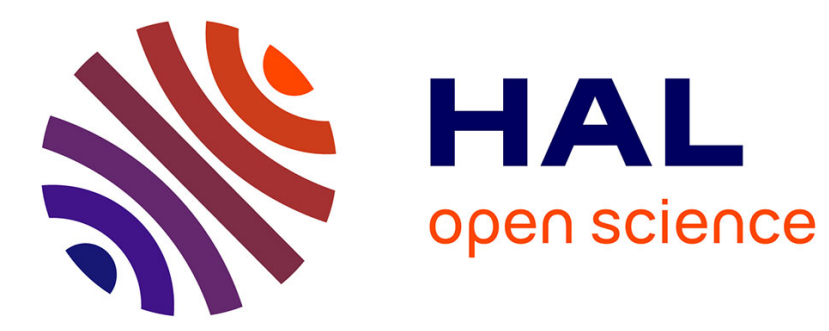

\title{
Extreme Value at Risk and Expected Shortfall during Financial Crisis
}

\author{
L. Kourouma, Denis Dupré, G. Sanfilippo, O. Taramasco
}

\section{To cite this version:}

L. Kourouma, Denis Dupré, G. Sanfilippo, O. Taramasco. Extreme Value at Risk and Expected Shortfall during Financial Crisis. 2011. halshs-00658495

\section{HAL Id: halshs-00658495 https://shs.hal.science/halshs-00658495}

Submitted on 10 Jan 2012

HAL is a multi-disciplinary open access archive for the deposit and dissemination of scientific research documents, whether they are published or not. The documents may come from teaching and research institutions in France or abroad, or from public or private research centers.
L'archive ouverte pluridisciplinaire HAL, est destinée au dépôt et à la diffusion de documents scientifiques de niveau recherche, publiés ou non, émanant des établissements d'enseignement et de recherche français ou étrangers, des laboratoires publics ou privés. 


\title{
CERAG
}

Centre d'Etudes et de Recherches Appliquées à la Gestion_U.M.R. C.N.R.S. 5820

\section{CAHIER DE RECHERCHE $n^{\circ} 2011-03$ E2}

Extreme Value at Risk and Expected Shortfall during Financial Crisis

\author{
Lanciné Kourouma \\ Denis Dupre \\ Gilles Sanfilippo \\ Ollivier Taramasco
}




\title{
Extreme Value at Risk and Expected Shortfall during Financial Crisis
}

\author{
Lanciné Kourouma $^{1}$, Denis Dupre ${ }^{2}$, Gilles Sanfilippo ${ }^{3}$, Ollivier Taramasco ${ }^{4}$ \\ CERAG UMR5820 - Doctoral School of Management \\ University of Grenoble - France
}

April 2011

\begin{abstract}
This paper investigates Value at Risk and Expected Shortfall for CAC 40, S\&P 500, Wheat and Crude Oil indexes during the 2008 financial crisis. We show an underestimation of the risk of loss for the unconditional VaR models as compared with the conditional models. This underestimation is stronger using the historical VaR approach than when using the extreme values theory VaR model. Even in 2008 financial crisis, the conditional EVT model is more accurate and reliable for predicting the asset risk losses. Banks have no interest in using it because the Basel II agreement penalizes banks using accuracy models like the conditional EVT model, and this is the case for the assets being studied in this paper.
\end{abstract}

JEL classification: C22; G10; G21

Keywords: Market risk, Value at Risk, EVT, GARCH, Financial crisis, Basel requirements

\footnotetext{
${ }^{1}$ IAE of Grenoble - CERAG UMR CNRS 5820 (CERAG, 150, rue de la chimie, BP 47, 38040 Grenoble cedex). E-mail : Lancine.Kourouma@upmf-grenoble.fr;

${ }^{2}$ IAE of Grenoble - CERAG UMR CNRS 5820 (CERAG, 150, rue de la chimie, BP 47, 38040 Grenoble cedex). E-mail : Denis.Dupré@upmf-grenoble.fr

${ }^{3}$ IAE of Grenoble - CERAG UMR CNRS 5820 (CERAG, 150, rue de la chimie, BP 47, 38040 Grenoble cedex). E-mail : Gilles.Sanfilippo@upmf-grenoble.fr

${ }^{4}$ ENSIMAG of Grenoble - CERAG UMR CNRS 5820 (CERAG, 150, rue de la chimie, BP 47, 38040 Grenoble cedex). E-mail : Ollivier.Taramasco@imag.fr
} 


\section{Introduction}

In recent years both practitioners and academics from the financial community have become interested in extreme events analysis particularly concerning financial risk management. From a practical point of view, protecting the financial system and investor's wealth against unpredictable catastrophic events such as the October 1987 stock market crash, the 2000 Internet bubble burst or the 2007 subprime crisis, calls for reliable tools to measure extreme risks. Indeed, the ability to estimate extreme market movements can be particularly useful for detecting risky portfolios.

Usually, risk estimation studies concentrate on two measures that attempt to describe the tail of a loss distribution - Value at Risk (VaR) and Expected Shortfall (ES). Value at Risk has become the standard measure of risk employed by financial institutions and their regulators. This risk measure can be defined as a high quantile of the distribution of losses, typically the 95th or 99th percentile. It provides a kind of upper bound for a loss that is only exceeded on a small proportion of occasions. However, some authors, like Artzner et al. (1999) have criticized VaR as a measure of risk on two grounds. First, VaR is not necessarily sub-additive meaning that $\mathrm{VaR}$ is not a coherent risk measure: there are cases where a portfolio can be split into sub-portfolios such that the sum of the VaR corresponding to the sub-portfolios is smaller than the VaR of the total portfolio. This may cause problems if the risk-management system of a financial institution is based on VaR-limits for individual books. Moreover, VaR tells us nothing about the potential size of the loss that exceeds it. Artzner et al. propose use of Expected Shortfall instead of VaR. The Expected Shortfall is the expected size of a loss that exceeds $\mathrm{VaR}$ and is coherent according to their definition.

The suitability of VaR approaches in practice is questionable in light of considerable evidence of the non-normality of market returns. In fact, the exact distribution of financial returns remains unknown. Stylized facts about the distribution of financial returns generally concur that at monthly and longer horizons, return series appear to be normally distributed. However, at weekly, daily and higher frequencies, return distributions consistently display non-normal features. Indeed, many authors like Agarwal et al. (2000), Michell et al. (2000) and Liang (1999) recognize that the returns' distributions have a leptokurtic and asymmetric shape. Obviously, the use of a normal approximation of the marginal return distribution results in underestimated tails and disregards excess kurtosis and skewness displayed by the empirical marginal distributions of returns. 
Extreme Value Theory (EVT) uses alternative distributions and focuses on the tail behavior of the asset returns. EVT methods have two features which make them attractive for tail estimation: they are based on a sound statistical theory, and they offer a parametric form for the tail of a distribution. Two main approaches are proposed in the literature to calibrate extreme value theory: the Block Maxima (BM) based on the Generalized Extreme Value (GEV) and the Peak Over Threshold (POT) based on the Generalized Pareto Distribution (GPD). Since the seminal work of Longin (1998), the empirical applicability of EVT to estimate extreme risks of real market data has been tested by several authors. Neftci (2000) and Fromont (2005) demonstrate that the unconditional VaR from the POT method is more accurate than that from the normal distribution. Da Silva et al. (2003) study ten Asian stock markets and show the accuracy of GEV VaR calculated over more one-month horizon. McNeil et al. (2000) first combine the generalized Pareto distribution and the GARCH model to estimate conditional VaR. Fernandez (2003) and Gençay et al. (2004) also combine GPD and GARCH model to measure conditional $\mathrm{VaR}$ on several emerging markets. Marimoutou et al. (2009) apply the conditional GPD to the crude oil. Assaf (2009) use conditional generalized Pareto distribution to model emerging market risks. The majority of these studies show the empirical superiority of EVT for VaR and ES estimation. Most of these studies focus on a one-day horizon and don't take into account the asymmetric returns.

In this study, we estimate Value at Risk and Expected Shortfall based on extreme value theory model and historical simulation approach and analyze their accuracy during the 2008 financial crisis. We take into account the volatility clustering and asymmetric return problems by introducing a GJR-GARCH model (Glosten, Jagannathan and Runkle, 1993) in the historical simulation and EVT methods. To our knowledge, implementation of the extreme value theory, (more particularly the generalized Pareto distribution) for VaR estimation has never been applied for more than a one day time horizon for measuring Value at Risk of financial assets, but there are several economic and practical reasons for computing long-term risk measures. The risk horizons longer than one day are particularly important for risk liquidity management, for long term strategic asset allocation and for capital requirements. The Basel Committee obliges banks to compute their risk over ten-day horizon. To sum up, our paper contributes to the literature in three ways. First, we introduce GJRGARCH in EVT model and Filtered Historical Simulation (FHS) approach to take into account volatility clustering and asymmetric returns. Second, we calculate VaR and ES over 5-day and 10-day horizons for risk liquidity management and Basel capital requirements. Finally, we focus on the accuracy of our risk models during the 2008 financial crisis, capital 
requirement measures and the opportunity of banks to choose a reliable model. The remainder of this paper is organized as follows. In Section 2 we present our data sample and its descriptive statistics. We present generalized Pareto distribution parameter estimate in section 3. We also check the adequacy between the empirical and theoretical generalized Pareto distributions. Section 4 explains relevant back-testing procedures for testing the accuracy of $\mathrm{VaR}$ and ES estimates. In section 5, our empirical results from the Historical Simulation method and EVT model are presented. Finally, Section 6 concludes and gives some suggestions for future research.

\section{Data sample and descriptive statistics}

Our study focuses on logarithmic returns of the CAC 40, S\&P 500 stock indexes and Wheat, Crude Oil commodity indexes, extracted from the Datastream database. The Wheat and Crude oil are taken from the Goldman Sachs Commodity Index (GSCI) of Standard and Poor. The study covers the period from January 1988 to December 2010 for all stock and commodity indexes. We have 6000 daily observations of logarithmic returns based on market closing price for each index. We calculate 5-day and 10-day returns by calculating the sum of daily returns. These returns are not overlapped. The choice of these indexes is motivated by their availability over a long period thus giving more extreme.

Table 1 presents descriptive statistics for the analysis of the logarithmic returns of CAC 40, S\&P 500, Wheat and Crude Oil. It gives an overview of the behavior of asset distributions for different time horizons. Excepting the Wheat, we observe that the skewness is negative for all time horizons, meaning that these stock and commodity indexes recorded returns lower than their average during the period which appears in the Gaussian model. Likewise, kurtosis is higher than 3 for the considered time horizons. We are thus confronted with a case of leptokurtic distributions, i.e. they have fat tails, in comparison with the normal distribution. These distributions do not follow normal distribution patterns confirmed by the Jarque-Bera test in Table 1. At first glance, the study of the behavior of the extremes in the left tails of these leptokurtic distributions seems justified as it should allow better estimation of extreme variations of financial returns. VaR and ES estimates based on the hypothesis of the normal distribution of returns must then be rejected and we need to compute them in the non-normal framework (EVT framework for example). 
Table 1

Descriptive statistics for different time horizons (data from January 1988 - December 2007)

\begin{tabular}{|c|c|c|c|c|c|c|c|c|}
\hline \multicolumn{9}{|c|}{ Descriptive Statistics } \\
\hline \multicolumn{2}{|l|}{ Returns } & Minimum & Maximum & Mean & Std. Deviation & Skewness & Kurtosis excess & Jarque Bera test (5\%) \\
\hline & Daily & -0.077 & 0.070 & 0.00 & 0.013 & $-0.142(0.03)$ & $3.179(0.07)$ & 0.00 \\
\hline & Weekly & -0.121 & 0.110 & 0.00 & 0.027 & $-0.151(0.08)$ & $1.15(0.15)$ & 0.00 \\
\hline \multirow[t]{3}{*}{ CAC 40} & 2 Weeks & -0.189 & 0.146 & 0.00 & 0.039 & $-0.369(0.11)$ & $1.142(0.21)$ & 0.00 \\
\hline & Daily & -0.071 & 0.056 & 0.00 & 0.009 & $-0.235(0.03)$ & $4.581(0.07)$ & 0.00 \\
\hline & Weekly & -0.123 & 0.075 & 0.00 & 0.021 & $-0.48(0.08)$ & $2.912(0.15)$ & 0.00 \\
\hline \multirow[t]{3}{*}{ S\&P 500} & 2 Weeks & -0.117 & 0.104 & 0.00 & 0.028 & $-0.257(0.11)$ & $1.593(0.21)$ & 0.00 \\
\hline & Daily & -0.061 & 0.079 & 0.00 & 0.015 & $0.225(0.03)$ & $1.676(0.07)$ & 0.00 \\
\hline & Weekly & -0.117 & 0.151 & 0.00 & 0.033 & $0.401(0.08)$ & $0.979(0.15)$ & 0.00 \\
\hline \multirow[t]{3}{*}{ GSCI Wheat } & 2 Weeks & -0.134 & 0.177 & 0.00 & 0.047 & $0.37(0.11)$ & $0.369(0.21)$ & 0.00 \\
\hline & Daily & -0.384 & 0.136 & 0.00 & 0.021 & $-1.359(0.03)$ & $24.922(0.07)$ & 0.00 \\
\hline & Weekly & -0.323 & 0.201 & 0.00 & 0.044 & $-0.575(0.08)$ & $3.964(0.15)$ & 0.00 \\
\hline GSCl Crude oil & 2 Weeks & -0.332 & 0.264 & 0.00 & 0.061 & $-0.349(0.11)$ & $2.403(0.21)$ & 0.00 \\
\hline
\end{tabular}

Weekly and 2 weeks returns are respectively the sum of 5 and 10 daily logarithmic returns of assets and they do not overlap. The numbers in parentheses are the standard error. Kurtosis excess is the kurtosis minus three. For all returns, the kurtosis is greater than three meaning the distribution curves have fat tails. CAC 40, S\&P 500 and Crude oil have skewed distributions. Wheat does not. The calculated p-values of Jarque Berra test are lower than chosen p-value and show our asset returns don't follow the normal distribution.

\section{Estimate of the tail distribution parameters with the POT method}

As we reject normality for the distribution of studied asset return series, we need to adequately fit the tail of the return distributions to estimate its risk parameters with EVT. Modeling extremes can be done in two different ways: by modeling the maximum of a collection of random variables or by modeling the largest values over some high threshold, known as the Peak Over Threshold method. We use the latter as it uses data more efficiently.

Let $\left(X_{1}, X_{2}, \ldots, X_{n}\right)$ be a sequence of independent and identically random variables from unknown distribution $\mathrm{F}$. We fix a sufficient threshold $u$. Consider $Y_{1}, Y_{2}, \ldots Y_{k}$ as the excesses above this threshold where $Y_{i}=X_{i}-u$.

Let us define the excess distribution above the threshold $u$ as the conditional probability:

$$
\begin{gathered}
F_{u}(y)=P(X-u / X>u) \\
F_{u}(y)= \begin{cases}\frac{F(u+y)-F(u)}{1-F(u)} & , y \geq 0 \\
0 & , y<0\end{cases}
\end{gathered}
$$

For $u$ large, the Gnedenko-Pickands-Balkema-deHaan theorem states that the distribution function converges to a generalised Pareto distribution.

$$
\lim _{u \rightarrow X_{0}} \operatorname{Sup} \underset{\substack{F_{u}(y)-G_{\xi, \sigma(u)}(y) \mid=0 \\ 0 \leq y<X_{0}-u}}{ }
$$


where $G_{\xi, \sigma}$ is the generalized Pareto distribution and given by:

$$
G_{\xi, \sigma}(y)= \begin{cases}1-\left(1+\frac{\xi y}{\sigma}\right)^{-1 / \xi}, & \xi \neq 0 \\ 1-\exp (-y / \sigma), & \xi=0\end{cases}
$$

where $y \geq 0$ for $\xi \geq 0$ and $0 \leq y \leq-\sigma / \xi$ for $\xi<0$.

The parameter $\xi$ determines the shape of the distribution, and in particular the decay of the left tail or heavy tailed behaviour. The parameter $\sigma$ is a scale parameter and the location parameter $u$ will be the threshold value. The generalized Pareto distribution subsumes three other distributions under its parameterization. So, when shape parameter $\xi=0$, we obtain a type 1 distribution (tails decrease exponentially) like the normal distribution. If $\xi<0$, we have a type 2 distribution (tails are finite) like a beta distribution. For $\xi>0$, we obtain a type 3 distribution (tails decrease polynomially) as student's t distribution. Assuming a GPD function for the tail distribution, analytical expressions for VaR and ES can be defined as a function of GPD parameters.

$$
\operatorname{VaR}_{\hat{q}}=u+\frac{\widehat{\sigma}}{\hat{\xi}}\left(\left(\frac{N}{N_{u}}(1-P)\right)^{-\hat{\xi}}-1\right)
$$

$N$ is the number of observations in the left tail and $N_{u}$ is the number of excesses beyond the threshold $u$.

The Expected Shortfall based on the GPD approach is defined as:

$$
E S_{\widehat{q}}=V a R_{\widehat{q}}+\frac{\sigma+\xi\left(V a R_{\widehat{q}}-u\right)}{1-\xi}=\frac{V a R_{\widehat{q}}}{1-\xi}+\frac{\sigma-\xi u}{1-\xi}
$$

\subsection{Conditional Generalized Pareto Distribution modelling}

To take into account the volatility clustering in our studied assets we combine the POT method and GARCH model as first suggested by McNeil and Frey (2000). GJR-GARCH type (Glosten, Jagannathan and Runkle, 1993) is used to model the conditional VaR. The advantage of this GARCH-EVT combination lies in its ability to capture conditional heteroscedascity in the data through the GARCH framework, while at the same time modeling the extreme tail behavior through the EVT method. GARCH models explicitly model the conditional volatility as a function of past conditional volatilities and returns. We assume that the dynamics of the return series follows the stochastic process of GJR-GARCH(1,1): 


$$
\begin{aligned}
& X_{t}=\mu_{t}+\varepsilon_{t}=\alpha_{0}+\alpha_{1} X_{t-1}+z_{t} \sigma_{g, t} \\
& \mu_{t}=\alpha_{0}+\alpha_{1} X_{t-1} \\
& \sigma_{g, t}^{2}=\beta_{0}+\beta_{1} \varepsilon_{t-1}^{2}+\varphi I_{\varepsilon_{t-1}<0} \varepsilon_{t-1}^{2}+\beta_{2} \sigma_{g, t-1}^{2}
\end{aligned}
$$

where $I_{\varepsilon_{t-1}}=0$ if $\varepsilon_{t-1}>0$ and $I_{\varepsilon_{t-1}}=1$ otherwise, that allows to take into account the sign of the residuals' disturbance. $\mu_{t}$ represents the conditional mean, $\varepsilon_{t}$ the residuals, $z_{t}$ the standardized residuals, $\sigma_{g, t}^{2}$ the variance and $\alpha_{n}, \beta_{n}$ are the parameters of the estimation.

The combined approach, denoted as conditional GPD, has the following steps:

- Step 1: Fit a GJR-GARCH model to the return data by quasi-maximum likelihood. That is, maximize the log-likelihood function of the sample assuming normal innovations. Estimate $\mu_{t}$ and $\sigma_{g, t}$ from the fitted model and extract the standardized residuals $Z_{t}$.

- Step 2: Consider the standardized residuals computed in step 1 to be realizations of a white noise process, and estimate the tails of the innovations using extreme value theory. Next, compute the quantiles of the innovations.

- Step 3: Construct VaR from parameters estimated in steps one and two. VaR is computing with le same formula in Eq. (6). The conditional Expected Shortfall is given by:

$$
E S_{\widehat{q}}=\mathrm{u}+\sigma_{\mathrm{g}}\left(\frac{V a R_{\hat{q}}}{1-\xi}+\frac{\sigma-\xi u}{1-\xi}\right)
$$

where $\sigma_{\mathrm{g}}$ is forecasted volatility from GJR-GARCH modeling.

By first filtering the returns with a GJR-GARCH model, we essentially get i.i.d. series on which it is straightforward to apply the EVT technique. The main advantage of the conditional generalized Pareto distribution is that it produces a VaR which reflects the current volatility background.

\subsection{Threshold choice for EVT}

To apply the GPD, we need to choose a reasonable threshold $u$, which determines the number of observations, $N_{u}$, in excess of threshold value. The choice of the threshold $u$ is an important issue: on one hand, if $u$ is too high, it results in too few excesses and consequently 
high variance estimators and on the other hand, if $u$ too small, it provides biased estimators and the approximation to a GPD is not feasible. It is possible to choose an asymptotically optimal threshold by a quantification of a bias versus variance trade-off. So far, no automatic algorithm with satisfactory performance for the selection of the threshold $u$ is available. For example, Gavin (2000) and Neftci (2000) arbitrarily chose to retain respectively $10 \%$ and 5 $\%$ of the sample while McNeil and Frey (2000) use the mean excess plot. (ME plot), defined in the following way:

$$
\begin{gathered}
\left\{\left(\mathrm{u}, \mathrm{e}_{\mathrm{n}}(\mathrm{u})\right), \mathrm{X}_{\mathrm{n}: \mathrm{n}}<u<\mathrm{X}_{1: \mathrm{n}}\right\} \\
e_{n}(u)=\frac{1}{N u} \sum_{i=1}^{N u}(X i-u)^{+}
\end{gathered}
$$

where $X_{1: n}$ et $X_{n: n}$ are respectively the maximums and the minimums of the sample and $e_{n}(u)$, the sum of the excesses over the threshold $u$ divided by the number $N u$ of data which exceed $u$. It is necessary to note that the mean excess function (ME) of the generalized Pareto distribution is:

$$
e_{n}(u)=\frac{\sigma+\xi u}{1-\xi}, \quad \xi<1
$$

The sample mean excess function, which is an estimate of the mean excess function, should be linear. This property can be used as a criterion for the selection of $u$. We observe that for the CAC 40 and Wheat indexes, the curves become almost linear when the threshold $u$ is equal to 0.02 . This threshold corresponds to small stock market variations and was also applied to S\&P 500 and Crude Oil indexes. Once a threshold for time horizon is chosen, the parameters $(\xi, \sigma)$ of the GPD can be computed.
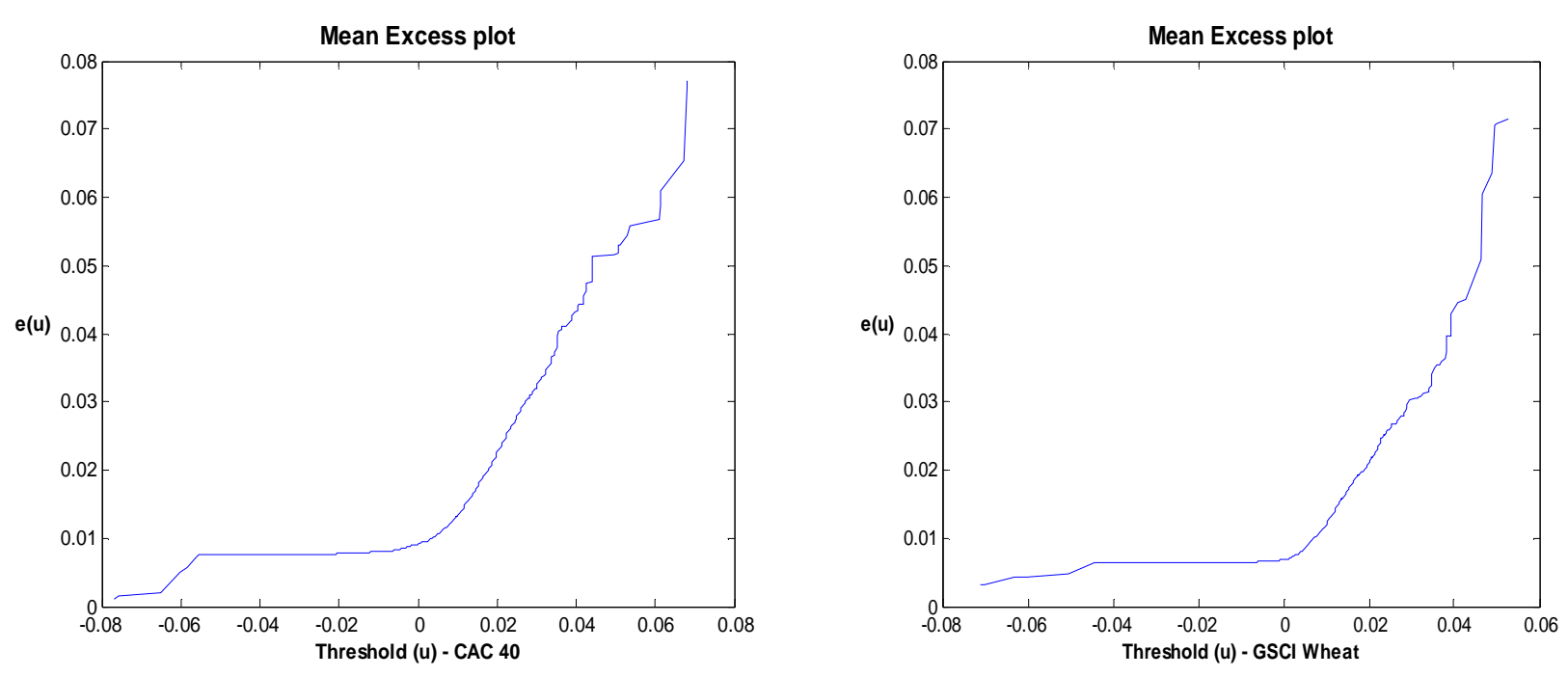

Fig.1. Mean Excess plot to choose thresholds of daily returns 
Different methods can be used to estimate the parameters of the GPD. In this paper we use the maximum likelihood estimation method. For a sample $y=\left\{y_{1}, \ldots, y_{n}\right\}$ the $\log$ likelihood function $L(\xi, \sigma \mid \mathrm{y})$ for the GPD is the logarithm of the joint density of the $n$ observations :

$$
L(\xi, \sigma \mid y)=\left\{\begin{array}{ll}
-n \log \sigma-\left(\frac{1}{\xi}+1\right) \sum_{i=1}^{n} \log \left(1+\frac{\xi}{\sigma} y_{i}\right) & \text { if } \xi \neq 0 \\
-n \log \sigma-\frac{1}{\sigma} \sum_{i=1}^{n} y_{i} & \text { if } \xi=0
\end{array}\right\}
$$

We compute the values $\xi$ and $\sigma$ that maximize the log-likelihood function for the sample defined by the observations exceeding the threshold $u$.

Table 2 presents the results of the estimation by the maximum likelihood method of the generalized Pareto distribution parameters, fitting the $\mathrm{N}_{\mathrm{u}}$ excess above the threshold $u$, for each time horizon. These results correspond to the average of the parameters' estimations over 250 observations for a 1-day horizon, 157 observations for a 5-day horizon and 100 observations for a 10-day horizon of the stock and commodity indexes. For all asset returns, except the 10-day horizon for wheat, the estimated tail index $\xi$ of generalized Pareto distribution is positive. Left tails of these return distributions are fat, i.e the probability of occurrence of extreme loss is higher than what the normal distribution predicts. However, for 10-day returns of Wheat, the average of the tail index is negative meaning these returns don't follow the normal distribution and the probability of occurrence of extreme loss is low.

Table 2

Estimated parameters of GPD

\begin{tabular}{|c|c|c|c|c|c|c|c|c|}
\hline \multicolumn{9}{|c|}{ GPD Parameters } \\
\hline \multicolumn{2}{|l|}{ Returns } & $\mathrm{N}$ & $\mathrm{Nu}$ & $\mu$ & $\xi$ & $\sigma$ & $(\xi)$ & $(\sigma)$ \\
\hline \multirow[b]{3}{*}{ CAC 40} & Daily & 2449 & 295 & 0.02 & 0.07 & 0.01 & 0.07 & 0.001 \\
\hline & Weekly & 489 & 170 & 0.025 & 0.07 & 0.02 & 0.07 & 0.002 \\
\hline & 2 Weeks & 220 & 94 & 0.03 & 0.12 & 0.03 & 0.11 & 0.004 \\
\hline \multirow[b]{3}{*}{ S\&P 500} & Daily & 2363 & 164 & 0.02 & 0.13 & 0.01 & 0.09 & 0.001 \\
\hline & Weekly & 462 & 99 & 0.025 & 0.22 & 0.01 & 0.13 & 0.002 \\
\hline & 2 Weeks & 221 & 59 & 0.03 & 0.08 & 0.02 & 0.12 & 0.004 \\
\hline \multirow[b]{3}{*}{ GSCl Wheat } & Daily & 2476 & 408 & 0.02 & 0.05 & 0.01 & 0.06 & 0.001 \\
\hline & Weekly & 519 & 235 & 0.025 & 0.01 & 0.02 & 0.06 & 0.002 \\
\hline & 2 Weeks & 270 & 143 & 0.03 & -0.07 & 0.03 & 0.06 & 0.003 \\
\hline \multirow[b]{3}{*}{ GSCI Crude oil } & Daily & 2407 & 674 & 0.02 & 0.15 & 0.01 & 0.04 & 0.001 \\
\hline & Weekly & 482 & 248 & 0.025 & 0.07 & 0.03 & 0.06 & 0.003 \\
\hline & 2 Weeks & 239 & 142 & 0.03 & 0.05 & 0.04 & 0.08 & 0.005 \\
\hline
\end{tabular}

$\mathrm{N}$ is the number of observations in the left tail distribution, $\mathrm{Nu}$ is the number of observations that exceed threshold $u$. $(\xi)$ and $(\sigma)$ respectively correspond to the standard error of shape parameter and scale parameter. The positive value of shape parameter $\xi$ means the probability of occurrence of extreme losses is high. 
To validate the previous results, we have to test the adequacy of the estimated asymptotic distributions to represent the behavior of the extreme returns of the considered assets. For that purpose, we use a graphical tool and a statistical test.

\subsection{Goodness of fit test}

To test adequacy between the empirical distribution of a variable and the theoretical distribution which in our special case is the generalized Pareto distribution, we first use a simple graphical tool: Quantile to Quantile plot (QQ-plot). The alignment of the points of QQ-plot (Fig. 2) shows that the estimated parameter of the GPD at the threshold 0.02 describes the behavior of the excesses in the left tail for daily asset returns.
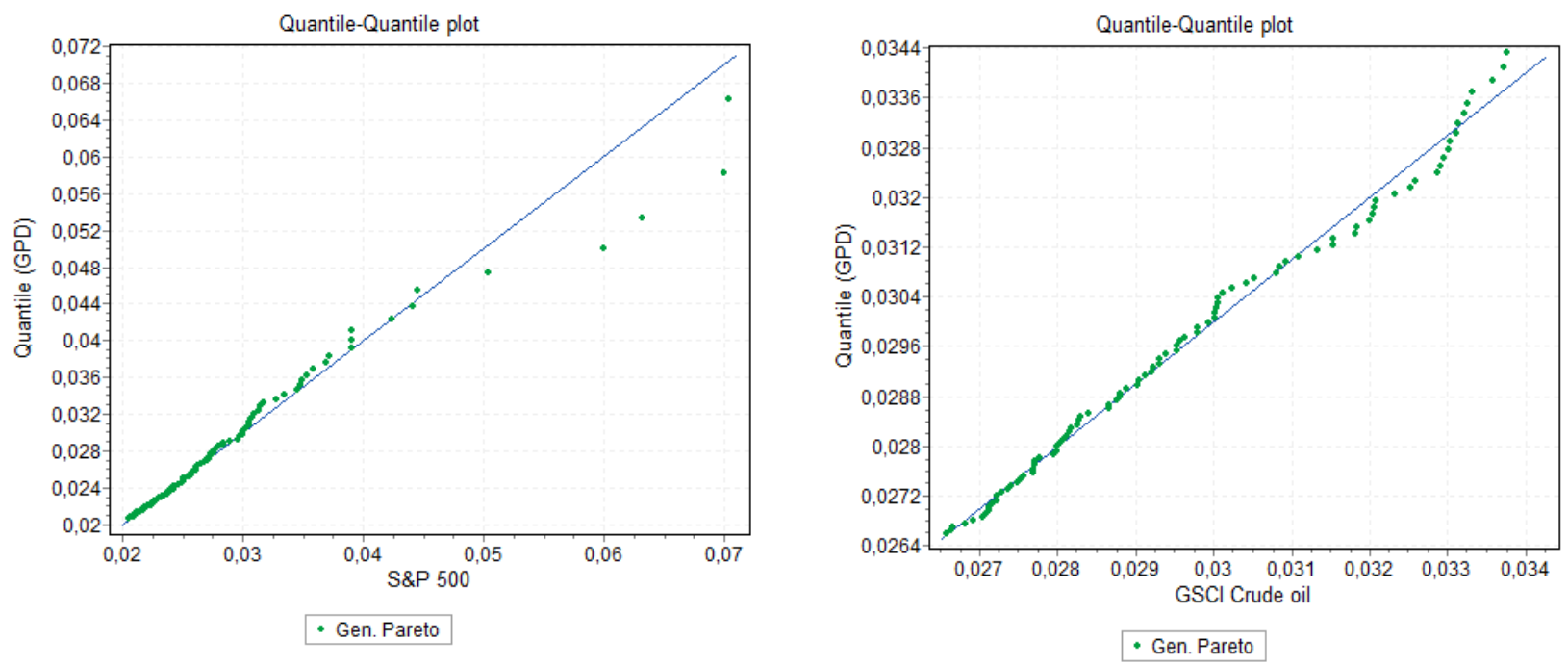

Fig.2. Quantile-Quantile plot of S\&P 500 and Crude oil

The Kolmogorov-Smirnov test is a nonparametric test of adjustment allowing measurement of the adequacy between an empirical distribution function and an estimated function. An attractive feature of this test is that the distribution of the K-S test statistic itself does not depend on the underlying cumulative distribution function being tested. The Kolmogorov-Smirnov test statistic D is defined as:

$$
D=\sup |F(y)-G(y)|
$$

This is asymptotically distributed as follows:

$$
P(\sqrt{n D}<y) \rightarrow G(y)=\sum_{-\infty}^{+\infty}(-1)^{k} e^{\left(-2 k^{2} y^{2}\right)}
$$


Where $F(y)$ and $G(y)$ represent the empirical distribution function and estimated function of the generalized Pareto distribution. The hypothesis regarding the distributional form is rejected if the test statistic $\mathrm{D}$ is greater than the critical value.

Table 3 provides the statistics of Kolmogorov-Smirnov obtained from the left tails of both assets. The difference between the empirical distribution and estimated function of the GPD seems to be not significant for a $95 \%$ confidence level because for all time horizons, the statistic D is lower than the critical value. From these results, the distribution of the extremes can be replaced by the estimated asymptotic laws because they have a relatively good fit with the empirical distributions of the tails. So, it becomes possible to estimate potential losses for the stock and commodity indexes in extreme market conditions.

Table 3

Kolmogorov-Smirnov test

\begin{tabular}{|c|c|c|c|c|}
\hline & & \multicolumn{3}{|c|}{ Kolmogorov Smirnov test } \\
\hline \multicolumn{2}{|l|}{ Returns } & Statistic D & Critical value & P-value (0.05) \\
\hline \multirow[b]{3}{*}{ CAC 40} & Daily & 0.03 & 0.08 & 0.97 \\
\hline & Weekly & 0.6 & 0.10 & 0.45 \\
\hline & 2 Weeks & 0.04 & 0.13 & 0.99 \\
\hline \multirow[b]{3}{*}{ S\&P 500} & Daily & 0.04 & 0.12 & 0.97 \\
\hline & Weekly & 0.05 & 0.13 & 0.89 \\
\hline & 2 Weeks & 0.08 & 0.16 & 0.68 \\
\hline \multirow[b]{3}{*}{ GSCI Wheat } & Daily & 0.03 & 0.07 & 0.87 \\
\hline & Weekly & 0.04 & 0.08 & 0.73 \\
\hline & 2 Weeks & 0.05 & 0.11 & 0.80 \\
\hline \multirow[b]{3}{*}{ GSCl Crude oil } & Daily & 0.05 & 0.14 & 0.97 \\
\hline & Weekly & 0.04 & 0.08 & 0.85 \\
\hline & 2 Weeks & 0.04 & 0.11 & 0.90 \\
\hline
\end{tabular}

The calculated P-values and statistic value of Kolmogorov-Smirnov test allow replacing the empirical distributions of the tails by the generalized Pareto distribution.

\section{Evaluating risk measure models accuracy}

In this section, we backtest our risk models using the Kupiec (1995) test and Wald test developed by Campbell (2005) for unconditional coverage and the Christoffersen (1998) test for conditional coverage. The backtesting procedure consists of comparing the VaR estimates with actual realized loss in the next period. We determine whether the frequency of exceedances is in line with the predicted confidence level VaR based on the unconditional coverage test. However, tests of unconditional coverage fail to detect violations of independence property of an accurate $\mathrm{VaR}$ measure, it is important to examine if the violations are also randomly distributed. An accurate VaR model must exhibit both the unconditional coverage and independence property, we jointly test both properties based on Christoffersen's (1998) conditional coverage test. To backtest Expected Shortfall, we follow 
the backtesting procedure used by Embrechts et al. (2005) in calculating a measure evaluating ES performance when returns are violating the corresponding VaR measure.

\subsection{Unconditional coverage test}

Let $N=\sum_{t=1}^{T} I_{t+1}$ be the number of days over a $\mathrm{T}$ period that the portfolio loss was larger than the $\mathrm{VaR}$ estimate, where $I_{t+1}$ is a sequence of $\mathrm{VaR}$ violations that can be described as:

$$
I_{t+1}=\left\{\begin{array}{ll}
1, & \text { if } X_{t+1}<V a R_{t+1} / t \\
0, & \text { if } X_{t+1} \geq \operatorname{VaR}_{t+1} / t
\end{array}\right\}
$$

We use a likelihood ratio test developed by Kupiec (1995). This test examines whether the failure rate $\alpha$ is statistically equal to the expected one. If the total number of such trials is $\mathrm{T}$, the number of failure $\mathrm{N}$ can be modeled with a binomial distribution with probability of occurrence equaling $\alpha$. The correct null and alternative hypothesis are, respectively $H_{0}: \frac{N}{T}=$ $\alpha$ and $H_{1}: \frac{N}{T} \neq \alpha$.

The appropriate likelihood ratio statistic is:

$$
L R_{u c}=2\left[\log \left(\left(\frac{N}{T}\right)^{N}\left(1-\frac{N}{T}\right)^{T-N}\right)-\log \left(\alpha^{N}(1-\alpha)^{T-N}\right)\right], \quad L R_{u c} \stackrel{d}{\rightarrow} x^{2}(1)
$$

$L R_{u c} \stackrel{d}{\rightarrow} x^{2}(1)$ under $H_{0}$ of good specification. Note that this backtesting procedure is a twosided test. Therefore, a model is rejected if it generates too many or too few violations, but based on it, the risk manager can accept a model that generates dependent exceptions.

The Kupiec test doesn't indicate if the risk model underestimates or overestimates the risk losses. To remedy that, we apply the Wald test which is defined by its statistic $\mathrm{z}$ :

$$
\mathrm{Z}=\frac{\sqrt{T}(\widehat{\alpha}-\alpha)}{\sqrt{\alpha(1-\alpha)}} \quad, \quad Z \stackrel{d}{\rightarrow} N(0,1)
$$

Where $\widehat{\alpha}$ is the risk level estimated by the model, $\alpha$ is the chosen risk level and T the size of retained backtesting window.

The hypothesis of unconditional coverage is rejected when statistic $\mathrm{z}$ is different from 0 or higher than the critical value of normal distribution associated with a certain confidence level. If the statistic is raised and negative, it means that the considered model significantly overestimates the risk of the asset while a positive value indicates an underestimation of the risk. Statistic $\mathrm{z}$ equal to zero indicates that the real number of $\mathrm{VaR}$ violations is identical at the risk level fixed for the calculation of the VaR. In this last scenario, it is considered that the model reliably allows in estimating asset risk. 


\subsection{Conditional coverage test}

The unconditional coverage test may fail to detect VaR measures that exhibit correct unconditional coverage but exhibit dependent VaR violations. So, we turn to a Christoffersen test, which jointly investigates if the VaR failure process is independently distributed through time. This test provides an opportunity to detect VaR measures which are deficient in one way or another. Under the null hypothesis that the failure process is independent and the expected proportion of violations is equal to $\alpha$, the appropriate likelihood ratio is:

$$
\begin{aligned}
L R_{c c}= & -2\left[\log \left(\alpha^{N}(1-\alpha)^{T-N}\right)\right] \\
& +2\left[\log \left(\left(1-\pi_{01}\right)^{n_{00}} \pi_{01}^{n_{01}}\right)\left(1-\pi_{11}\right)^{n_{10}} \pi_{11}^{n_{11}}\right], \quad \operatorname{Lcc} \stackrel{d}{\rightarrow} x^{2}(2)
\end{aligned}
$$

Where $n_{i j}$ is the number of observations with value $i$ followed by $j$, for $i, j=0,1$ and $\pi_{i j}=\frac{n_{i j}}{\sum_{j} n_{i j}}$ are the corresponding probabilities. The values $i, j=1$ denote that a violation has been made, while $i, j=0$ indicates the opposite. The main advantage of this test is that it can reject a VaR model that generates either too many or too few clustered violations.

\subsection{Expected Shortfall backtesting}

To backtest the ES forecasts, we calculate the average difference between the realized returns and the forecasted ES's, conditional on having a (negative) returns exceeding the corresponding VaR estimate.

The test statistic is defined as follows:

$$
V=\frac{\sum_{t=1}^{n}\left(X_{t}-\left(E S_{t, p}\right)\right) I_{X_{t}<V a R_{t, p}}}{\sum_{t=1}^{n} I_{X_{t}<V a R_{t, p}}}
$$

Given this formula, the negative value of the statistic indicates the underestimation of risk losses and the positive value, the risk losses' overestimation. ES measures are accurate when the value of the $V$ tends to zero.

We choose to test the risk models over 250 days for a 1-day horizon, over 157 weeks for a 5-day horizon and over 100 2-weeks for a 10-day horizon. This time window of 250 working days was recommended by the Basel committee as a backtesting window for the validation of internal models of market risk measure. Besides, in the document "Risk Management: In practical Guides" of the RiskMetrics group, this window is fixed at 90 days 
minimum to obtain significant results. These periods includes the time of the Lehman Brothers ${ }^{5}$ bankruptcy corresponding to the bottom of the 2008 financial crisis.

\section{Empirical results}

Our empirical analysis differs from previous empirical research in two respects. First, most previous research has analyzed only $\mathrm{VaR}$ at the $95 \%$ and $99 \%$ confidence levels. To better reflect the extreme market conditions of this research we consider confidence levels for $\mathrm{VaR}$ and ES of 95\%, 99\% and 99.5\%. The accuracy of our measures is assessed using 5,216 observations for a 1-day horizon, 1,042 observations for a 5-day horizon and 499 observations for a 10-day horizon. Second, to take into account for market liquidity constraints and Basel regulations we consider a 5-day and 10-day risk horizons in addition to the more typical 1-day horizon. That allows calculating VaR over 10-day horizon without multiplying by the square root of 10. This rule is problematic for VaR measurement using the EVT model. According to the extreme value theory, to compute VaR over a time horizon, the daily VaR must be multiplied by the time horizon exponent of the tail index value of the generalized Pareto distribution which is less than 0.5 for financial assets. Following this rule, the VaR measures of the EVT model will underestimate financial risks. Each time VaR and ES are estimated, they are based on revised parameter estimates using the most recent estimation window of 5,216 days, 1,042 weeks and 499 10-days for different time horizon. At the end of each risk horizon we calculate actual profit and loss for the trading portfolio. An exceedance occurs if the loss is greater than the estimated VaR or ES for that horizon. These exceedances are imputs to the tests of unconditional coverage, conditional coverage and ES backtest. Tables 4 and 5 present results for the unconditional and conditional Historical Simulation and EVT methods.

Clearly the unconditional HS method performs no better in tests of unconditional coverage (column (i.d) and column (i.e)) and of conditional coverage (column (i.f)). The performance in measuring ES (column (i.g)) is poor for different time horizons. The Wald test on the unconditional HS method indicates a strong underestimation for stock and commodity indexes over 1-day horizon. These underestimations decrease when the time horizon increases.

\footnotetext{
${ }^{5}$ Lehman Brothers was an Investment bank in the USA which went bankrupt on September 15th, 2008 during the 2008 financial crisis.
} 
Table 4

Unconditional risk models backtesting

\begin{tabular}{|c|c|c|c|c|c|c|c|c|c|c|c|}
\hline \multirow{2}{*}{$\begin{array}{l}\text { Assets } \\
\text { (a) }\end{array}$} & \multirow{2}{*}{$\begin{array}{l}1-\alpha \\
\text { (b) }\end{array}$} & \multicolumn{5}{|c|}{ (i) Unconditional HS } & \multicolumn{5}{|c|}{ (ii) Unconditional EVT } \\
\hline & & $\begin{array}{c}\text { VaR violations } \\
\text { (c) }\end{array}$ & $\begin{array}{l}\text { Wald test } \\
\text { statistic } \\
\text { (d) }\end{array}$ & $\begin{array}{l}\text { Kupiec test } \\
\text { statistic } \\
\text { (e ) }\end{array}$ & $\begin{array}{l}\text { Christoffersen } \\
\text { test statistic } \\
\text { (f) }\end{array}$ & $\begin{array}{c}\text { ES test } \\
\text { statistic } \\
(\mathrm{g})\end{array}$ & $\begin{array}{c}\text { VaR violations } \\
\text { (c) }\end{array}$ & $\begin{array}{l}\text { Wald test } \\
\text { statistic } \\
\text { (d) }\end{array}$ & $\begin{array}{c}\text { Kupiec test } \\
\text { statistic } \\
\text { (e ) }\end{array}$ & $\begin{array}{c}\text { Christoffersen } \\
\text { test statistic } \\
\text { (f) }\end{array}$ & $\begin{array}{l}\text { ES test } \\
\text { statistic } \\
(\mathrm{g})\end{array}$ \\
\hline \multicolumn{12}{|l|}{ 1-day horizon } \\
\hline \multirow[t]{3}{*}{ CAC 40} & 95.00 & $40(0.00)$ & $7.98(0.00)$ & $41.37(0.00)$ & $41.37(0.00)$ & -0.0098 & $26(0.00)$ & $3.92(0.00)$ & $11.87(0.00)$ & $11.87(0.00)$ & -0.0104 \\
\hline & 99.00 & $19(0.00)$ & $9.22(0.00)$ & $37.04(0.00)$ & $37.04(0.00)$ & -0.0089 & $13(0.00)$ & $6.67(0.00)$ & $22.32(0.00)$ & $22.32(0.00)$ & -0.0052 \\
\hline & 99.50 & $13(0.00)$ & $10.54(0.00)$ & $37.95(0.00)$ & $37.95(0.00)$ & -0.0062 & $9(0.00)$ & $6.95(0.00)$ & $20.28(0.00)$ & $20.78(0.00)$ & -0.0024 \\
\hline \multirow[t]{3}{*}{ S\&P 500} & 95.00 & $50(0.00)$ & $10.88(0.00)$ & $69.89(0.00)$ & $69.89(0.00)$ & -0.0131 & $39(0.00)$ & $7.69(0.00)$ & $38.82(0.00)$ & $38.82(0.00)$ & -0.0113 \\
\hline & 99.00 & $27(0.00)$ & $15.57(0.00)$ & $82.01(0.00)$ & $82.01(0.00)$ & -0.0115 & $18(0.00)$ & $9.85(0.00)$ & $41.06(0.00)$ & $41.27(0.00)$ & -0.0105 \\
\hline & 99.50 & $21(0.00)$ & $17.71(0.00)$ & $80.61(0.00)$ & $80.61(0.00)$ & -0.0082 & $13(0.00)$ & $10.54(0.00)$ & $37.95(0.00)$ & $38.98(0.00)$ & -0.0074 \\
\hline \multirow[t]{3}{*}{ GSCI Wheat } & 95.00 & $60(0.00)$ & $13.78(0.00)$ & $103.44(0.00)$ & $103.44(0.00)$ & -0.0109 & $43(0.00)$ & $8.85(0.00)$ & $49.35(0.00)$ & $49.35(0.00)$ & -0.0106 \\
\hline & 99.00 & $33(0.00)$ & $19.39(0.00)$ & $113.22(0.00)$ & $113.22(0.00)$ & -0.0068 & $25(0.00)$ & $14.30(0.00)$ & $72.24(0.00)$ & $72.24(0.00)$ & -0.0040 \\
\hline & 99.50 & $24(0.00)$ & $20.40(0.00)$ & $98.48(0.00)$ & $98.48(0.00)$ & -0.0052 & $18(0.00)$ & $15.02(0.00)$ & $63.67(0.00)$ & $63.67(0.00)$ & -0.0015 \\
\hline \multirow[t]{3}{*}{ GSCI Crude Oil } & 95.00 & $36(0.00)$ & $6.82(0.00)$ & $31.57(0.00)$ & $31.57(0.00)$ & -0.0078 & $25(0.00)$ & $3.63(0.00)$ & $10.33(0.00)$ & $12.30(0.00)$ & -0.0023 \\
\hline & 99.00 & $17(0.00)$ & $9.22(0.00)$ & $37.04(0.00)$ & $37.04(0.00)$ & 0.0097 & $6(0.01)$ & $2.22(0.01)$ & $3.56(0.06)$ & $3.56(0.17)$ & 0.0051 \\
\hline & 99.50 & $7(0.00)$ & $5.16(0.00)$ & $12.75(0.00)$ & $14.32(0.00)$ & 0.0154 & $4(0.01)$ & $2.47(0.01)$ & $3.84(0.05)$ & $3.84(0.15)$ & 0.0150 \\
\hline \multicolumn{12}{|l|}{ 5-day horizon } \\
\hline CAC 40 & 99.00 & $6(0.00)$ & $3.55(0.00)$ & $7.36(0.01)$ & $7.37(0.03)$ & -0.0249 & $3(0.07)$ & $1.15(0.13)$ & $1.04(0.31)$ & $1.04(0.59)$ & -0.0566 \\
\hline S\&P 500 & 99.00 & $7(0.00)$ & $4.36(0.00)$ & $10.26(0.00)$ & $10.91(0.00)$ & -0.0058 & $3(0.07)$ & $1.15(0.13)$ & $1.04(0.31)$ & $5.52(0.63)$ & -0.0227 \\
\hline GSCI Wheat & 99.00 & $12(0.00)$ & $8.37(0.00)$ & $28.67(0.00)$ & $28.67(0.00)$ & -0.0086 & $7(0.00)$ & $4.35(0.00)$ & $10.26(0.00)$ & $10.91(0.00)$ & -0.0150 \\
\hline GSCI Crude Oil & 99.00 & $5(0.01)$ & $2.75(0.00)$ & $4.80(0.03)$ & $6.91(0.03)$ & -0.0031 & $2(0.21)$ & $0.35(0.37)$ & $0.11(0.74)$ & $0.11(0.95)$ & -0.0360 \\
\hline \multicolumn{12}{|l|}{10 -day horizon } \\
\hline CAC 40 & 99.00 & $3(0.02)$ & $2.01(0.02)$ & $2.63(0.11)$ & $2.63(0.27)$ & -0.0495 & $2(0.08)$ & $1.01(0.16)$ & $0.78(0.38)$ & $0.78(0.68)$ & -0.0547 \\
\hline S\&P 500 & 99.00 & $4(0.00)$ & $3.02(0.00)$ & $5.18(0.02)$ & $5.19(0.08)$ & -0.0362 & $2(0.08)$ & $1.01(0.16)$ & $0.78(0.38)$ & $0.78(0.68)$ & -0.0957 \\
\hline GSCI Wheat & 99.00 & $4(0.00)$ & $3.01(0.00)$ & $5.18(0.02)$ & $5.19(0.08)$ & -0.0385 & $2(0.08)$ & $1.01(0.16)$ & $0.78(0.38)$ & $0.78(0.68)$ & -0.0809 \\
\hline GSCI Crude Oil & 99.00 & $3(0.02)$ & $2.01(0.02)$ & $2.63(0.11)$ & $6.22(0.27)$ & -0.0046 & $1(0.26)$ & $0.00(0.50)$ & $0.00(1.00)$ & $0.00(0.99)$ & -0.0749 \\
\hline
\end{tabular}

(a) The trading portfolio used for the analysis. (b) The confidence level at which VaR and ES are calculated. (c) The number of times that VaR is exceeded by real losses. (d) and (e) Test of null hypothesis that the actual number of violations is equal to the expected number of violations. (f) Joint test of the null hypothesis that violations spread evenly over time. ( $g$ ) Test the underestimation or the overestimation of losses beyond the VaR. The back-testing runs from January, 2008 to December, 2008 for the 1-day horizon, from January, 2008 to December, 2010 for the 5-day horizon and from Mars, 2007 to December, 2010 for the 10-day horizon.

The values in the parentheses correspond at the p-value which must compare to $\alpha$ for columns (c) and (d) concerning respectively $\mathrm{VaR}$ violations and the Wald test. For Kupiec and Christoffersen tests, p-value has to compare to $5 \%$.

Considering the unconditional EVT model, its backtesting results in Table 4 shows a slight underestimation of risk losses for our stock and commodity indexes at a 1-day horizon. However, according to Wald, Kupiec and Christoffersen tests, the unconditional EVT model performs better over 5-day and 10-day horizons. The Expected Shortfall based on the EVT model is poor but less than that of the Historical Simulation method. That is, the ES $\left(\mathrm{ES}^{6}\right.$ test statistic in column (i.g) and (ii.g) of Table 4) underestimate the true potential losses beyond the VaR. The unconditional EVT model performs better in backtesting test than the unconditional Historical Simulation method. The EVT model has advantages to be modeled on the extreme left tail of asset returns. However, both models underestimate risk losses at a 1-day horizon. This underestimation can be explained in part by the presence of the clustering volatility. To take into account this clustering volatility, we introduce in our risk models the GJR-GARCH modeling to compute the conditional VaR and ES' measures. Moreover, this

\footnotetext{
${ }^{6}$ The negative values of ES test statistic indicate the real losses are superior to the expected shortfall value. Embrechts et al. (2005) take the absolute of this statistic to appreciate the model accuracy. Don't take the absolute value make sense to know about model underestimation or model overestimation.
} 
GARCH type takes into account the sign of residuals disturbance which has an impact on the volatility. After taking into account volatility and asymmetric problems in our risk models, we backtest them in the same way as the previous unconditional risk models.

Turning to the conditional Historical Simulation (or Filtered Historical Simulation FHS) method presented in Table 5, we observe that while modeling heteroscedasticity improves performance, especially in terms of unconditional coverage (columns (i.d) and (i.e)) and conditional coverage (column (i.f)). There are slight underestimate according to the positive values of the Wald test. The Filtered Historical Simulation method performance is rejected by the backtesting procedure on the Wheat index at a 1-day horizon. The ES statistic (column (i.g) in Table 5) show that the conditional ES slightly underestimates risk losses. However, it performs better than its unconditional estimate at a 1-day horizon.

Table 5

Conditional risk models backtesting

\begin{tabular}{|c|c|c|c|c|c|c|c|c|c|c|c|}
\hline \multirow{2}{*}{$\begin{array}{l}\text { Assets } \\
\text { (a) }\end{array}$} & \multicolumn{6}{|c|}{ 1- $\alpha$ (i) Conditional FHS } & \multicolumn{5}{|c|}{ (ii) Conditional EVT } \\
\hline & (b) & $\begin{array}{c}\text { VaR violations } \\
\text { (c) }\end{array}$ & $\begin{array}{l}\text { Wald test } \\
\text { statistic } \\
\text { (d) }\end{array}$ & $\begin{array}{l}\text { Kupiec test } \\
\text { statistic } \\
\text { (e) }\end{array}$ & $\begin{array}{c}\text { Christoffersen } \\
\text { test statistic } \\
\text { (f) }\end{array}$ & $\begin{array}{c}\text { ES test } \\
\text { statistic } \\
(\mathrm{g})\end{array}$ & $\begin{array}{c}\text { VaR violations } \\
\text { (c) }\end{array}$ & $\begin{array}{l}\text { Wald test } \\
\text { statistic } \\
\text { (d) }\end{array}$ & $\begin{array}{c}\text { Kupiec test } \\
\text { statistic } \\
\text { (e) }\end{array}$ & $\begin{array}{l}\text { Christoffersen } \\
\text { test statistic } \\
\text { (f) }\end{array}$ & $\begin{array}{c}\text { ES test } \\
\text { statistic } \\
(\mathrm{g}) \\
\end{array}$ \\
\hline \multicolumn{12}{|l|}{ 1-day horizon } \\
\hline \multirow[t]{3}{*}{ CAC 40} & 95.00 & $24(0.00)$ & $3.34(0.00)$ & $8.88(0.00)$ & $9.23(0.01)$ & -0.0002 & $9(0.81)$ & $-1.02(0.85)$ & $1.14(0.29)$ & $1.15(0.56)$ & 0.5800 \\
\hline & 99.00 & $5(0.04)$ & $1.59(0.06)$ & $1.96(0.16)$ & $1.96(0.38)$ & -0.0051 & $2(0.46)$ & $-0.32(0.62)$ & $0.11(0.75)$ & $0.11(0.95)$ & 0.5700 \\
\hline & 99.50 & $3(0.04)$ & $1.57(0.06)$ & $1.77(0.18)$ & $1.77(0.41)$ & -0.0083 & $2(0.13)$ & $0.67(0.25)$ & $0.54(0.28)$ & $0.38(0.83)$ & 0.5826 \\
\hline \multirow[t]{3}{*}{ S\&P 500} & 95.00 & $20(0.01)$ & $2.18(0.02)$ & $4.04(0.04)$ & $4.04(0.13)$ & -0.0023 & $11(0.60)$ & $-0.44(0.67)$ & $0.20(0.66)$ & $0.22(0.90)$ & 0.5727 \\
\hline & 99.00 & $5(0.04)$ & $1.59(0.06)$ & $1.96(0.17)$ & $1.96(0.38)$ & -0.0030 & $2(0.46)$ & $-0.32(0.62)$ & $0.11(0.74)$ & $0.11(0.95)$ & 0.5769 \\
\hline & 99.50 & $3(0.38)$ & $1.57(0.06)$ & $1.76(0.18)$ & $1.77(0.41)$ & -0.0010 & $0(0.71)$ & $-1.12(0.87)$ & $2.50(0.11)$ & $2.51(0.29)$ & 0.0000 \\
\hline \multirow[t]{3}{*}{ GSCI Wheat } & 95.00 & $48(0.00)$ & $10.31(0.00)$ & $63.76(0.00)$ & $63.76(0.00)$ & -0.0097 & $17(0.08)$ & $1.34(0.10)$ & $1.54(0.21)$ & $1.54(0.46)$ & 0.5608 \\
\hline & 99.00 & $27(0.00)$ & $15.57(0.00)$ & $82.01(0.00)$ & $82.01(0.00)$ & -0.0072 & $1(0.71)$ & $-0.95(0.83)$ & $1.18(0.28)$ & $1.18(0.56)$ & 0.5658 \\
\hline & 99.50 & $22(0.00)$ & $18.61(0.06)$ & $86.47(0.00)$ & $86.47(0.00)$ & -0.0037 & $0(0.71)$ & $-1.12(0.87)$ & $2.50(0.11)$ & $2.51(0.29)$ & 0.0000 \\
\hline \multirow[t]{3}{*}{ GSCI Crude Oil } & 95.00 & $18(0.05)$ & $1.60(0.06)$ & $2.26(0.13)$ & $2.26(0.32)$ & 0.0036 & $8(0.88)$ & $-1.31(0.90)$ & $1.94(0.16)$ & $2.94(0.23)$ & 0.6041 \\
\hline & 99.00 & $2(0.46)$ & $-0.32(0.11)$ & $0.09(0.74)$ & $0.11(0.95)$ & 0.0182 & $1(0.71)$ & $-0.95(0.83)$ & $1.18(0.28)$ & $1.18(0.56)$ & 0.6235 \\
\hline & 99.50 & $0(0.71)$ & $-1.12(0.87)$ & $2.51(0.11)$ & $2.51(0.29)$ & 0.0000 & $0(0.71)$ & $-1.12(0.87)$ & $2.50(0.11)$ & $2.51(0.29)$ & 0.0000 \\
\hline \multicolumn{12}{|l|}{ 5-day horizon } \\
\hline CAC 40 & 99.00 & $3(0.07)$ & $1.15(0.13)$ & $1.04(0.31)$ & $1.04(0.59)$ & -0.0678 & $2(0.21)$ & $0.35(0.37)$ & $0.11(0.74)$ & $0.11(0.95)$ & 0.4520 \\
\hline S\&P 500 & 99.00 & $3(0.07)$ & $1.15(0.13)$ & $1.04(0.31)$ & $5.52(0.06)$ & -0.0547 & $3(0.07)$ & $1.15(0.13)$ & $1.04(0.31)$ & $5.52(0.63)$ & 0.5420 \\
\hline GSCI Wheat & 99.00 & $4(0.02)$ & $1.95(0.03)$ & $2.66(0.10)$ & $2.66(0.26)$ & -0.0119 & $2(0.21)$ & $0.35(0.37)$ & $0.11(0.74)$ & $0.11(0.95)$ & 0.5594 \\
\hline GSCl Crude Oil & 99.00 & $5(0.01)$ & $2.75(0.00)$ & $4.80(0.03)$ & $6.91(0.03)$ & 0.0229 & $2(0.21)$ & $0.35(0.37)$ & $0.11(0.74)$ & $0.11(0.95)$ & 0.6193 \\
\hline \multicolumn{12}{|l|}{10 -day horizon } \\
\hline CAC 40 & 99.00 & $2(0.08)$ & $1.01(0.16)$ & $0.78(0.38)$ & $0.78(0.68)$ & -0.1044 & $2(0.08)$ & $1.01(0.16)$ & $0.78(0.38)$ & $0.78(0.68)$ & 0.4873 \\
\hline S\&P 500 & 99.00 & $4(0.00)$ & $3.02(0.00)$ & $5.18(0.02)$ & $5.19(0.08)$ & -0.0507 & $3(0.02)$ & $2.01(0.02)$ & $2.63(0.11)$ & $2.63(0.27)$ & 0.5484 \\
\hline GSCI Wheat & 99.00 & $3(0.02)$ & $2.01(0.02)$ & $2.63(0.11)$ & $6.22(0.27)$ & -0.0302 & $2(0.08)$ & $1.01(0.16)$ & $0.78(0.38)$ & $0.78(0.68)$ & 0.4724 \\
\hline GSCI Crude Oil & 99.00 & $1(0.26)$ & $0.00(0.50)$ & $0.00(1.00)$ & $0.00(0.99)$ & -0.1305 & $1(0.26)$ & $0.00(0.50)$ & $0.00(1.00)$ & $0.00(0.99)$ & 0.3948 \\
\hline
\end{tabular}

(a) The trading portfolio used for the analysis. (b) The confidence level at which VaR and ES are calculated. (c) The number of times that VaR is exceeded by real losses. (d) and (e) Test of null hypothesis that the actual number of violations is equal to the expected number of violations. (f) Joint test of the null hypothesis that violations spread evenly over time. (g) Test the underestimation or the overestimation of losses beyond the VaR. The back-testing runs from January, 2008 to December, 2008 for the 1-day horizon, from January, 2008 to December, 2010 for the 5-day horizon and from Mars, 2007 to December, 2010 for the 10-day horizon.

The values in the parentheses correspond at the p-value which must compare to $\alpha$ for columns (c) and (d) concerning respectively VaR violations and the Wald test. For Kupiec and Christoffersen tests, p-value has to compare to $5 \%$.

The risk models based on the Extreme Value Theory (EVT) are much more suited to risk measurement, especially in the conditional case (Fig.3). Results for conditional EVT are 
presented in panel (ii) of Table 5. In all the cases we cannot reject the unconditional and conditional coverages. We find that the conditional Expected Shortfall (positive ES statistic value in Table 5, column (ii.g)) based on the EVT performs better than that of the conditional Historical Simulation approach. The negative values of the Wald test statistic indicate slight overestimation of risk losses. The conditional EVT risk model for VaR measurement is accurate according to all backtesting procedures for all assets and time horizons. We note, however, that the Expected Shortfall based on the conditional EVT largely overestimate the potential losses beyond the VaR.
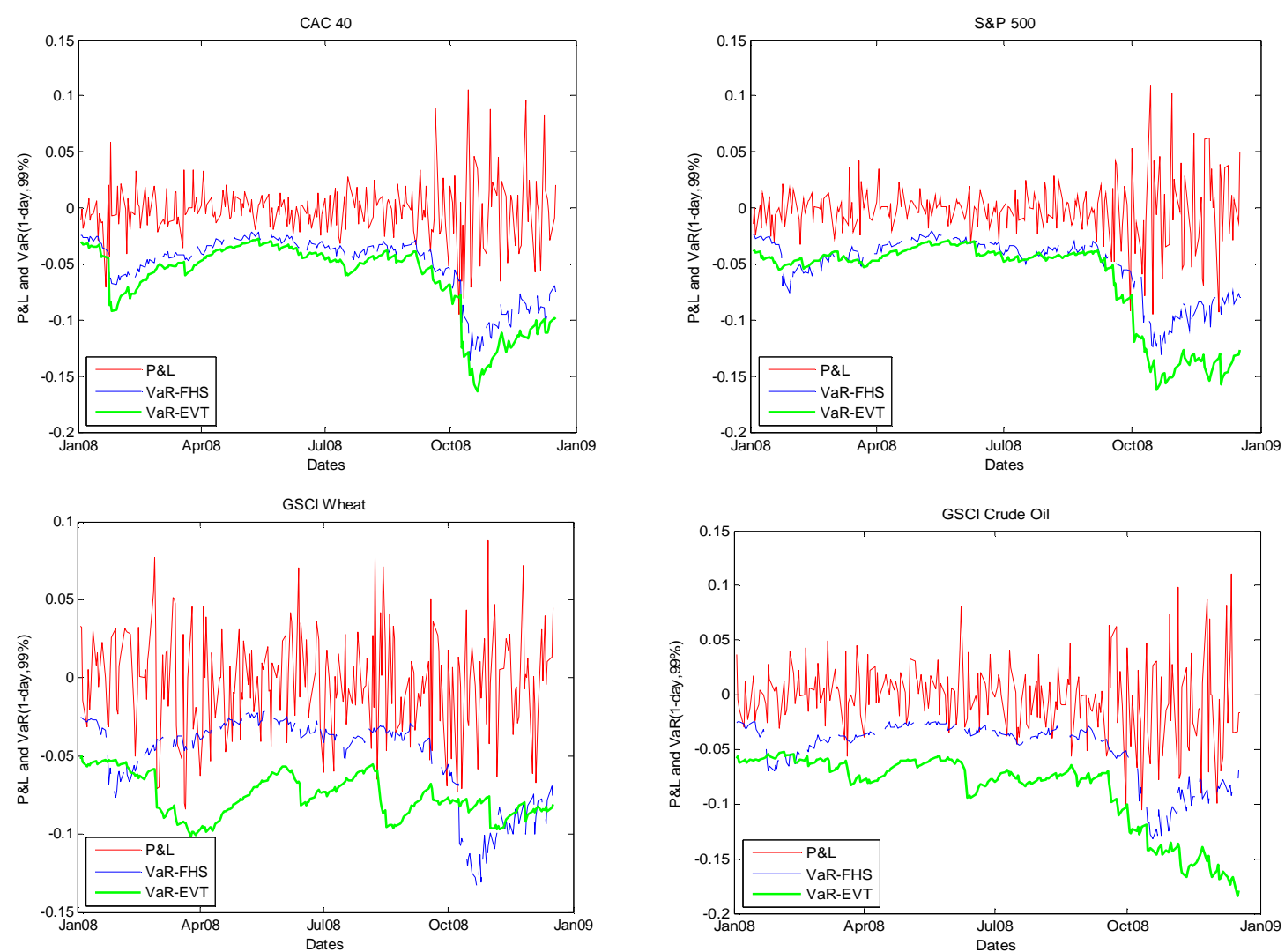

Fig.3. Backtesting results of the conditional EVT model and the Historical Simulation approach on CAC 40, S\&P 500, Wheat and Crude Oil. Backtesting window is 250 days and the VaR are calculated at $99 \%$ confidence level and over 1-day horizon.

Coming back to banking supervision in which the Capital adequacy Directive defined in 1996 concerning market risks is still in force today. Our calculated values of risk measurement have to be multiplied by the multiplicative factor: "Each bank must meet, on a daily basis, a capital requirement expressed as the higher of its previous day's value-at-risk number measured according to the parameters specified in this section and an average of the daily value-at-risk measures on each of the preceding sixty business days, multiplied by a multiplicative factor. The multiplicative factor will be set by individual supervisory 
authorities on the basis of their assessment of the quality of the bank's risk management system, subject to an absolute minimum of 3.”
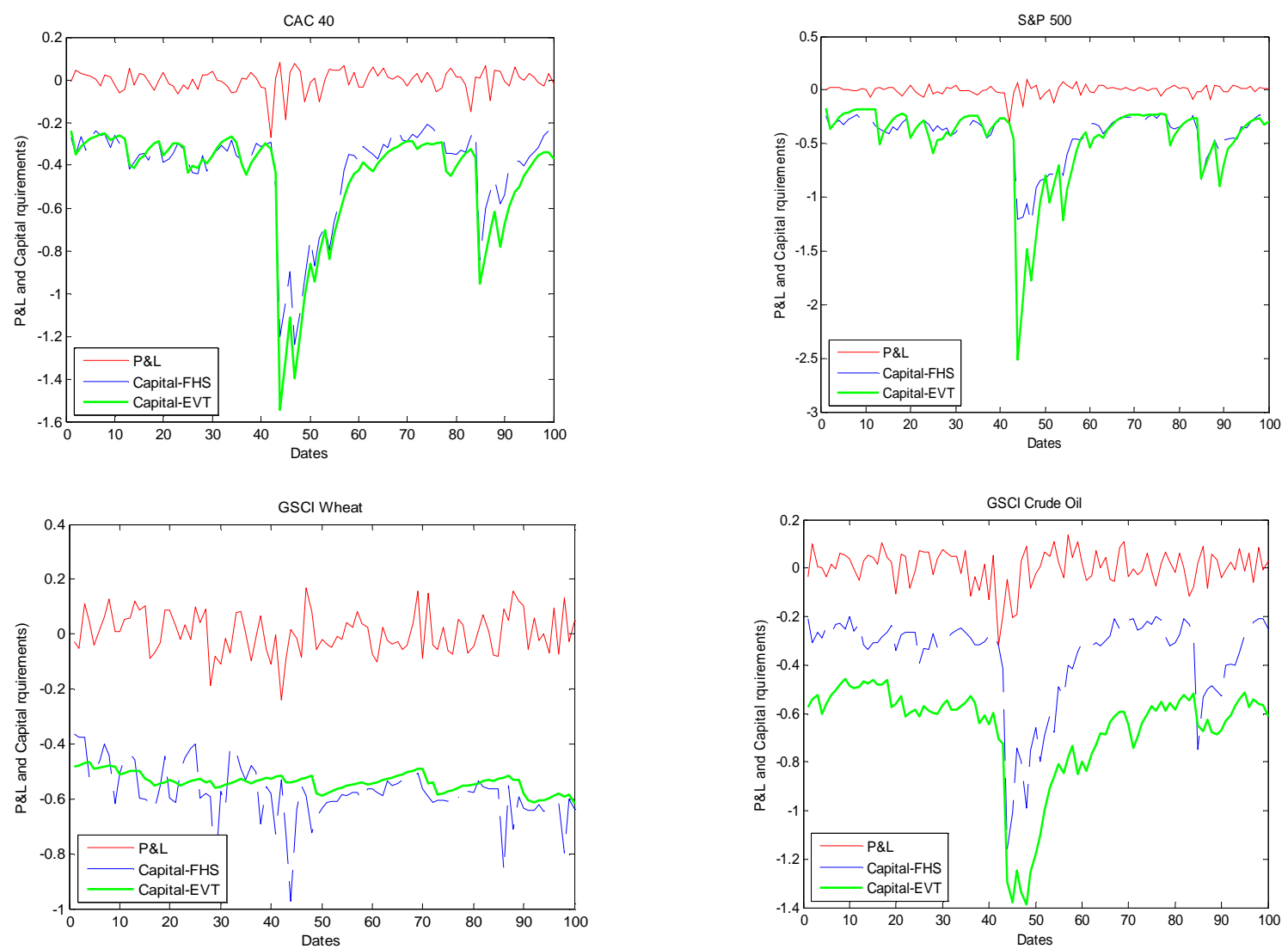

Fig.4. Capital requirements under Basel rule for FHS and conditional EVT

Capital requirements calculated as $3 V_{a R_{0.01,10-d a y}}$ for conditional EVT (exceptions less than 5 for all assets) and $3.4 V a R_{0.01,10-d a y}$ for FHS (5 exceptions for CAC 40). The multiplier is 3 for all assets under conditional EVT model. It is 3 for Crude Oil, 4 for Wheat and 3.4 for CAC 40 and S\&P 500 under FHS approach.

According to the regulatory backtesting requirements, banks must calibrate $\mathrm{VaR}$ measures to daily profit and loss observations, and these VaR are predicated on a 99\% confidence level. Backtesting must also be performed daily. If the number of VaR violations during the previous 250 business days is fewer than 5 , the multiplier is 3 ; if the number of $\mathrm{VaR}$ violations is 5, the multiplier is 3.40 , and so on; and 10 or more exceptions warrant a multiplier of 4. In this context and according to the backtesting results in Table 5 for our studied stock and commodity indexes, the conditional EVT model respects Basel II requirements (see fig.4). We observe that the number of exceptions using the conditional EVT model is 2 or 1 , and that these are largely inferior to 5. Following this Basel rule, banks can choose a non accuracy model like FHS with the aim to optimizing their capital cushion. 


\section{Conclusion}

The estimation of the generalized Pareto distribution fitting the extreme returns allows us to bring to light the existence of fat tails. So, the risk of extreme loss on stock and commodity indexes is higher than the occurrence of expected gains. The study reveals that the tails index of the generalized Pareto distribution on returns are generally positive. These results particularly confirm the previous research results over 1-day horizon. We also find that these results are valid over 5-day and 10-day horizons. The last time horizon allows computing capital requirement over 10-day horizon.

Through backtesting procedures, the unconditional Historical Simulation fails to accurately measure risk losses on the studied assets (CAC 40, S\&P 500, Wheat and Crude Oil). We observe strong underestimation of VaR and Expected Shortfall measures using Historical Simulation approach. Comparatively, the unconditional EVT model performs better at 5-day and 10-day horizons but less well at a 1-day horizon. For both the unconditional risk models, the number of $\mathrm{VaR}$ violations decreases when the confidence level increases. The underestimation also decreases when the time horizon rises.

We demonstrate in this study that introducing GJR-GARCH modeling in the EVT model to compute conditional $\mathrm{VaR}$ is more reliable for measuring financial risks in normal and abnormal market conditions. The backtesting results in panel (ii) of Table 5 show the accuracy of our conditional EVT VaR measures for all studied assets. We note, however, a strong overestimation for the Expected ShortFall measures based on the conditional EVT model. Even in the 2008 financial crisis, the conditional EVT model is more accurate and reliable for predicting the asset risk losses. We note the rules relating the capital multiplier to the number of exceptions are arbitrary, and there are concerns that the high scaling factor could discourage banks from developing and implementing best practices.

For future research, it would be interesting to broaden this study to multivariate EVT modeling by taking into account asset correlation problems. Modeling stress testing using EVT model is a challenging area in respect to the Basel III perspective. 


\section{Appendix A: standard Historical Simulation method}

Let $X_{1}, X_{2}, \ldots, X_{n}$ be as $\mathrm{n}$ random variables independently and identically distributed measuring the daily returns of an investment at the moments $1,2, \mathrm{n}$ which is defined by the unknown cumulative distribution function F. The VaR at $\alpha$ risk level can be defined by:

$$
\operatorname{VaR}_{\alpha}(X)=\text { Quantile }\left(\left(X_{t}\right)_{t=1}^{n}\right)
$$

where $X_{1} \leq X_{2} \leq \cdots \leq X_{n}$

Expected Shortfall based on the historical simulation method is defined by:

$$
E S_{\alpha}(X)=\mathrm{E} \llbracket \mathrm{X} / \mathrm{X}>\operatorname{VaR} \rrbracket
$$

\section{Appendix B: Filtered Historical Simulation method}

The Filtered Historical Simulation approach combines the historical simulation and the conditional volatility models like GARCH. To estimate volatility, we use GJR-GARCH $(1,1)$ model, which in addition to the characteristics of GARCH model, has a leverage effect (positive and negative return have different impact on volatility). This volatility can be obtained by:

$$
\sigma_{g, t}^{2}=\beta_{0}+\beta_{1} \varepsilon_{t-1}^{2}+\varphi I_{\varepsilon_{t-1}<0} \varepsilon_{t-1}^{2}+\beta_{2} \sigma_{g, t-1}^{2}
$$

Where $\varphi$ reflects an asymmetric effect on volatility whether the last period random residuals was positive or negative.

The return is calculated with first-order autoregressive AR(1) model.

$$
\begin{gathered}
X_{t}=\mu_{t}+\varepsilon_{t}=\mu_{t}+z_{t} \sigma_{g, t} \\
\mu_{t}=\alpha_{0}+\alpha_{1} X_{t-1}
\end{gathered}
$$

where $\mu_{t}$ is the conditional mean. The parameters $\alpha_{n}$ and $\beta_{n}$ are derived from Maximum Likelihood Estimation.

To make residuals $\varepsilon_{t}$ suitable for historical simulation, we divide residuals by conditional volatility forecast $\sigma_{t}$ to obtain standardized residuals $z_{t}$.

$$
z_{t}=\frac{\varepsilon_{t}}{\sigma_{g, t}}
$$

That series of standardized residuals are then updated with forecasted volatility $\hat{\sigma}_{t+1}$ to obtain current market condition 


$$
\hat{z}_{t+1}=z_{t} \hat{\sigma}_{g, t+1}
$$

Simulated returns can be generated by:

$$
\hat{X}_{t+1}=\mu_{t}+\hat{z}_{t+1}
$$

Therefore, we can calculate desired VaR in Eq. (23) and ES in Eq. (24) for each simulated return series at chosen confidence level. For a complete discussion on the use of historical simulation approach for VaR estimation, you can see various articles such as Hendriks (1996) and Barone-Adesi et al. (2000). 


\section{References}

Alexander, C. and Sheedy, E. (2008), Developping a stress testing framework based on market risk models, Journal of Banking and Finance, 32, 2220-2236.

Artzner, P. (2001), Application of coherent risk measures to capital requirements in Insurance, North American Actuarial Journal, $\mathrm{N}^{\circ} 3,11-25$.

Artzner, P., Delbaen, F., Eber, J. M. and Heath, D. (1999), Coherent Measure of Risk, Math. Fin, Vol. 9 (3), 203-228.

Assaf, A. (2009), Extreme observations and risk assessment in the equity markets of MENA region: Tail measures and Value-at-Risk, International review of Financial Analysis, $\mathrm{N}^{\circ}$ $18,109-116$.

Balkena, A., De Haan, L. (1974), Residual life at great age, Annals of Probability 2, 792-804.

Barone-Adesi, G., Bourgoin, F., Giannopoulos, K. (1998), Don't look back, Risk 11, 100-103.

Barone-Adesi, G., Giannopoulos, K., Vosper, L. (2000), Filtered Historical Simulation. Backtest Analysis, University of Westminster.

Basak, S., Shapiro, A. (2001), Value-at-risk-based risk management: optimal policies and asset prices, Review of Financial Studies, 14, 371-405.

Basel Committee on Banking Supervision, (1996), Amendement to the Capital Accord to Incorporate Market Risks.

Basel Committee on Banking Supervision, (2006), International Convergence of Capital Measurement and Capital standards: A Revised Framework Comprehensive Version (Bank for International Settlements, Basel).

Bollerslev, T. (1986), Generalised autoregressive conditional heteroskedasticity, Journal of Econometrics, 31, 309-328.

Campbell, S.D. (2005), A review of backtesting and backtesting procedures. Finance and Economics Discussion Series Division of Research Statistics and Monetary. Affairs Federal Reserve Board, Washington, D.C.

Christoffersen, P., Hahn, J., Inaoue, A. (2001), Testing and comparing value-at-risk measures, Journal of Empirical Finance, 8, 325-342.

Coles, S. (2001), An Introduction to Statistical Modeling of Extreme Values, Spring series in statistics, Springer-Verlag London Limited.

Da Silva, A.C., and Mendez, B. V. D. M. (2003), Value at Risk and extreme Returns in Asian Stock Markets, International Journal of Business, 8, 17-40.

Dowd, K. (2005), Measuring market risk, Willey Finance.

Embrechts, P. (2000), Extremes and Integrated Risk Management, published in association with UBS Warburg and Risk Books.

Embrechts, p., Kluperberg, C., Mikosch, T. (1997), Modeling Extremal Events for insurance and finance, Springer.

Embrechts, P., Resnick, C., Samorodnitsky, G. (1999), Extreme Value Theory as a Risk Management Tool, North American Actuarial Journal, 3, 30-41.

Embrechts, P., Kauffman, R., Patie, P. (2005), Strategic Long-Term Financial Risks: Single Risk Factors, Computational Optimization and Applications, 32, 61-90.

Engle, R.F., Manganelli, S. (1999), CAViaR : Conditional autoregressive value at risk by regression quantiles, Journal of Business \& Economic Statistics, 22, 367-381.

Fernandez, V. (2003), Extreme value theory and value-at-risk, Departement of industrial engineering at the University of Chile (DII).

Fromont, E. (2005), Modélisation des rentabilités extrêmes des distributions des Hedge,Funds, CREM UMR CNRS 6211- Axe Macroéconomie et Finance.

Gencay, R., Selcuk, F. (2004), Extreme Value Theory and Value at Risk: Relative Performance in Emerging Markets, International Journal of Forecasting, 20, 287-303.

Haas, M. (2001), New methods in backtesting, Working paper, Financial engineering research 
center caesar Bonn.

Haas, M. (2005), Improved duration-based backtesting of value-at-risk, Working paper, Institute of Statistics, University of Munich.

Jorion, P. (2002), Value at Risk, Second edition, McGraw Hill, New York.

Liang, B. (1999), On the Performance of hedge Funds, Journal of Finance and Quantitative Analysis, 35, 383-408.

Kupiec, P. (1995), Techniques for verifying the accuracy of risk management models, Journal of Derivatives, 3, 73-84.

Lopez, J. A. (1999), Regulatory evaluation of value-at-risk models, Journal of Risk, 1, 37-64.

Longin, F. (1998), Value at Risk: Une nouvelle approche fondée sur les valeurs extrêmes, Annales d'Economie et Statistiques, 52, 1-29.

Longin, F. (2000), From value at risk to stress testing: the extreme value approach, Journal of Banking and Finance, 24, 1097-1130.

Longin, F. (2001), Beyond the VaR, The Journal of Derivatives, 8, 36-48.

McNeil A.J., Frey, R. (2000), Estimation of tail-related risk measures for heteroscedastic financial time series : an extreme value approach, Journal of Empirical Finance, 7, 271- 300.

Michell and Pulvino. (2000), Characteristics of risk in risk arbitrage, Working paper, Harvard.

Nefci, S. (2000), Value at Risk Calculations, Extreme Events, and Tail Estimation, The Journal of Derivatives, 1-15.

Pickands, J. (1975), Statistical inference using extreme order statistics, Annals of Statistics, 3, 119-131.

Reiss, R.D., Thomas, M. (2001), Statistical Analysis of Extreme Values: from Insurance, Finance, Hydrology and Other Fields, Birkhauser Verlag, Basel.

Rockafellar, R. T., Uryasev, S. (2001), Conditional VaR for general loss distributions, Journal of Banking and Finance, 26(7), 1443-1471.

Timotheos, A., Degiannakis, S. (2006), Backtesting VaR models: an expected shortfall approach, Working paper, Athens University of Economics and Business.

Velayoudoum, M., Bechir, R., Abdelwahed,T. (2009), Extreme Value Theory and Value at Risk: Application to oil market, Energy Economics, 31, 519-530.

Vladimir, O., et al. (2009), An application of EVT, GPD and POT methods in Russian market Oryol Regional Academy of State Service, Oryol, 5. 